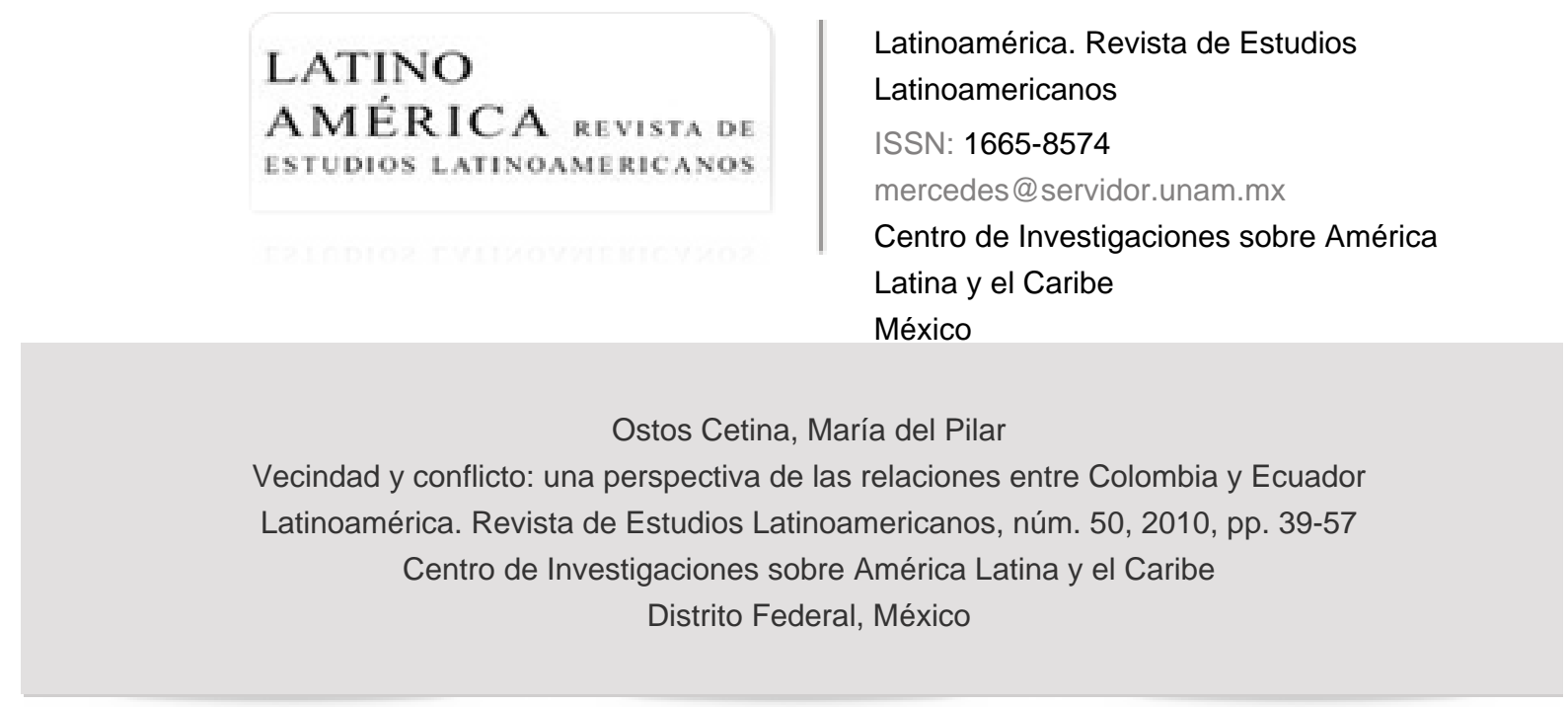

Disponible en: http://www.redalyc.org/articulo.oa?id=64014997004

- Cómo citar el artículo

- Número completo

- Más información del artículo

- Página de la revista en redalyc.org

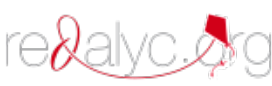

Sistema de Información Científica

Red de Revistas Científicas de América Latina, el Caribe, España y Portugal Proyecto académico sin fines de lucro, desarrollado bajo la iniciativa de acceso abierto 


\title{
Vecindad y conflicto: una perspectiva de las relaciones entre Colombia y Ecuador
}

\author{
María del Pilar Ostos Cetina*
}

Resumen: Este artículo analiza el desarrollo de las relaciones entre Colombia y Ecuador desde una perspectiva del espacio, la frontera y el conflicto armado. Para lo cual se recurren a elementos históricos, pero también se hace mención a la formación de las primeras organizaciones armadas y sus repercusiones en el ámbito del desarrollo del Estado colombiano y de su relación con los páses vecinos; lo que ha dado lugar en Colombia a la formación de un modelo de fragmentación territorial heredado de la época precolombina y virreinal, que durante los siglos XX y XXI se ha transformado en un tipo de conflicto armado o de guerra civil, como consecuencia de una disputa por el control políico del territorio colombiano y de sus recursos naturales.

PalaBRas ClavE: Frontera, Conflicto armado, Poblamiento fragmentado, Bases militares.

ABSTRAC: This article analyzes the development of relations between Colombia and Ecuador from a vision of space, the border and armed conflict. For which resort to its historical, but also mentions the formation of the first armed organizations and their impact on the development sector of the Colombian state and its relationship with neighboring countries; this has led to the formation in Colombia of a territorial fragmentation model inherited from the pre-Columbian and Colonial, which so far during the twenty-first century and has become a kind of armed conflict or civil war, following a political struggle for control of Colombia's territory and its natural resources.

Key words: Frontier, Armed conflict, Fragmented stocking, Military bases.

Becaria de la Coordinación de Humanidades en el Centro de Investigaciones sobre América Latina y el Caribe. Agradezco a la Coordinación de Humanidades ( $\mathrm{CH}$ ) por el apoyo que me ha brindado (mpostos@yahoo.com). 


\section{ANTECEDENTES HISTÓRICOS}

L a meta final de Cristóbal Colón en 1492 fue arribar, en sus tres carabelas, a las Indias orientales al tomar una ruta más rápida y efectiva por el Atlántico, lo cierto fue que convencido de haberlo logrado, tras encontrar tierra firme en aguas del mar Caribe y no del Índigo, su primera impresión frente a los nativos que habitaban aquellas tierras de profundo verdor y exuberancia natural fue bautizarlos con el apelativo de "indios".

A partir de entonces, el territorio indio recién hallado en ese Nuevo Mundo, que más adelante asumirá el nombre de América, ${ }^{1}$ quedó a merced de estos navegantes transatlánticos, quienes se dedicaron a hacer minuciosas y exhaustivas exploraciones en diferentes direcciones a lo largo y ancho del territorio recién encontrado. Situación que con el paso del tiempo sorprendió a los exploradores europeos, quienes quedaron atónitos frente a la incalculable riqueza natural, pero también ante el avanzado nivel de progreso alcanzado por estos pueblos indígenas, que ostentaban una adelantada organización geopolíica, socioeconómica, militar e incluso, científica y religiosa.

Por lo mismo, las exploraciones de los europeos se convirtieron en una frenética, pero también arriesgada búsqueda que los condujo a descubrir prominentes civilizaciones e imperios ancestrales, acaudalados de todo tipo de riquezas naturales; situación que los impulsó todavía más a someter a los máximos jefes políticos y militares aborígenes, para de este modo erigirse como los nuevos dueños y señores de estas tierras del Nuevo Mundo.

Así, sobre la estructura imperial y el diseño geopolítico alcanzado por los imperios precolombinos más relevantes, como fue el caso de los mayas y de los

1 De acuerdo con De Castro, el nombre de América tiene varios orígenes. Por un lado, algunos estudiosos lo atribuyen al nombre que los indígenas le daban a un macizo ubicado en Nicaragua. Otros aseguran que proviene de la ciudad indígena - Americapana - en la costa venezolana de Cumaná. Pero también está la versión en la que se afirma que tras la expedición del italiano Américo Vespucio y el envío de su correspondencia a Italia narrando los hallazgos descubiertos en el Nuevo Mundo, se adoptó su nombre para bautizar ese nuevo territorio visto por Vespucio al otro lado del Atlántico. Véase Teresina De Castro, Nossa América. Geopolítica comparada, Río de Janeiro, Biblioteca do Exército Editora, 1994, pp. 15 y 16. 
aztecas $^{2}$ en México y Centroamérica, emergió el virreinato de mayor influencia para la Corona española en la parte norte del Nuevo Mundo; mientras que en la parte sur del continente el turno era para el imperio Inca, el cual también desplegaba un notable poderío de riquezas, que se extendían desde el Ecuador hasta la parte norte de Argentina, convirtiéndose así en el otro polo de poder más atractivo para las pretensiones mercantilistas de los europeos.

Esto supone que los europeos de esta época, ante el deseo de acumulación de riquezas, no se detuvieron hasta despojar de sus más importantes baluartes a los antiguos pobladores indígenas, quienes se vieron acosados y sometidos al trabajo exhaustivo de la extracción de metales preciosos que, como el oro y otros minerales, salieron a través de las costas del Mar del Sur (del Pacífico) para alcanzar los litorales de Castilla de Oro (Panamá), Cartagena y Cuba con rumbo hacia la portentosa Europa, que se debatía en medio de todo tipo de lujos, extravagancias y de acaudalados navegantes, quienes se convertirían, de un día para otro, en empresarios de esta nueva compañía transoceánica.

Frente a tales hechos, el máximo objetivo al que aspiraron los exploradores de ultramar - ante esta sacrificada travesía por selvas, ríos, empinadas montañas, desiertos y caminos a medio hacer-consistiría en descubrir el famoso "Dorado", que más allá de convertirse en una simple leyenda pasó a ser la mayor motivación de todos los que anhelaron reunir todas las riquezas para sí.

Justamente en ese intento por descubrir un camino hacia el "Dorado", los conquistadores se encontraron con otro imperio, uno intermedio geográficamente entre los dominios azteca e inca, conocido como el imperio chibcha, ${ }^{3}$ concentrado principalmente en el área colombiana, venezolana y una parte colindante con el Ecuador, territorio sobre el cual más adelante los españoles establecerían el Virreinato de la Nueva Granada. ${ }^{4}$

2 Felipe Cárdenas Arroyo, "América: tres civilizaciones y numerosas sociedades intermedias", en Revista Credencial Historia, núm. 34, Bogotá, octubre, 1992.

3 Sylvia Broadbent, Los chibchas: organización social y política, Bogotá, Facultad de Sociología, Universidad Nacional de Colombia, 1964, p. 9.

4 Diego Montaña Cuellar, Colombia: país formal y país real, Buenos Aires, Platina, 1963, p. 46. 
Cabe resaltar que a diferencia de los mayas-aztecas e incas, los chibchas no lograron estructurarse como un imperio homogéneo, sino que más bien fueron un mosaico de muchos grupos dispersos, sin un centro político visible y escasamente intercomunicados; así su interacción fue complicada con los dos imperios vecinos, lo que impidió la creación de un sólido y verdadero puente cultural entre la América precolombina del norte y la del sur.

Así, una primera reflexión derivada de estos hechos del pasado respecto a las dos naciones vecinas de Colombia y Ecuador, durante la etapa precolombina, da cuenta de una constante que se atribuye a la escasa intercomunicación que existía entre ambos territorios, situación que se convertiría en la coyuntura perfecta para el "intervencionismo" de los primeros colonizadores extranjeros. La falta de alianzas entre los pobladores nativos y sus vecinos, la inexistencia de una resistencia militar organizada, además del incipiente desarrollo tecnológico en materia de comunicaciones y de transportes fueron, entre otros factores, los más convenientes para los intereses foráneos, que se vieron beneficiados ante este "poblamiento fragmentado" que ha privado desde entonces hasta la actualidad. ${ }^{5}$

Más tarde, durante el periodo colonial, la idea del poblamiento fragmentado se acentuó tras el aumento de la densidad poblacional de aquellas ciudades, apostadas sobre el corredor andino hasta el mar Caribe, principalmente Guayaquil, Quito, Popayán, Bogotá, Cartagena y Caracas, que fueron de notable importancia para las autoridades virreinales y eclesiásticas, debido a las condiciones topográficas y climatológicas que ofrecen los Andes para Ecuador y Colombia, lo mismo que la costera-montañosa en el caso de Venezuela, por ser estos lugares los más favorables para la clase política, europea y criolla, que prefirió mantenerse apartada de las zonas del trópico y de la selva húmeda cercana a la franja ecuatorial.

Durante la Colonia, Colombia formó parte del Virreinato del Perú, sin embargo, el condicionante geográfico impidió al virrey de Lima ejercer su autoridad real sobre tierras tan distantes y aisladas por la cordillera andina de la capital peruana. Por esa razón, en 1564, se designó la Real Audiencia de Santa Fe en el

5 Sobre la tesis de la fragmentación territorial en Colombia, se recomienda el trabajo elaborado por Marco Palacios, País fragmentado, sociedad dividida, su bistoria, Bogotá, Norma, 2002. 
territorio de Nueva Granada, que tendría la función de administrar las zonas venezolana y colombiana, con excepción en ambos casos de la jurisdicción del área de Caracas y la esquina suroccidental que incluía a Cali y Popayán, esta última gobernada por el presidente de Quito (Ecuador), quien realizaba las mismas funciones que un capitán general, con menor influencia en el ámbito militar.

En 1717, la Real Audiencia de la Nueva Granada fue elevada a categoría de virreinato por derecho propio, y los lazos que la unían con el Perú desaparecieron. Eso hizo que años más tarde se logrará consolidar plenamente el Virreinato de la Nueva Granada (1739), en esencia para atenuar y controlar las rivalidades que se presentaban en el Caribe; situación que se hacía justificable para la Corona, al tener a la mano oficiales de alto rango virreinal en el norte de América del Sur. Respecto a las presidencias de Quito y Panamá, éstas quedaron anexas al Virreinato de la Nueva Granada y no a Perú, situación que no las supeditó plenamente al control que se ejercía desde Santa Fe de Bogotá, precisamente por el condicionante geográfico y la carencia de vías de comunicación más ágiles; lo cual siguió privilegiando la comunicación por el Pacífico entre Panamá, Ecuador hasta el Perú. ${ }^{6}$

En esa misma época, la estrategia de concentración de agrupaciones negras e indígenas, perfectamente localizadas en nichos especializados en la producción agrícola y minera, llevaría a la exclusión de aquellos territorios "vacíos", como son la parte de los llanos orientales y de la selva amazónica, distantes e inaccesibles convertidos en espacios con escaso valor estratégico para las autoridades centrales hasta hace unos años, cuando se descubrieron importantes reservas de hidrocarburos y de otros recursos naturales y energéticos de notable valor en la industria moderna de hoy.

Ante la persistencia histórica de un modelo territorial diferenciado por su geografía, se crearían después nuevas unidades desintegradas en el área andina, la inminente "balcanización" de la que fuera llamada por Bolívar la Gran Colombia,

6 David Bushnell, Colombia una nación a pesar de sí misma. De los tiempos precolombinos a nuestros días, Bogotá, Planeta, 1996, p. 34. 
se presentó como una continuación de dicho modelo de ruptura, que en 1830 no fue más que la esfumación de los planes del Libertador por alcanzar una América grande y unida, esto debido al ánimo separatista que reinaba entre sus detractores, convencidos de la creación de entidades más pequeñas y declaradas independientes unas de otras, por lo que comenzó a asimilarse la idea entonces, del establecimiento de naciones independientes. Lo que desde otra perspectiva daría cuenta de la formación de "archipiélagos biológicos", como lo afirma el geopolítico colombiano, Julio Londoño, en alusión a aquellos espacios geográficos que se han creado separadamente a partir de ciertas barreras naturales llámense ríos, montañas, selvas, llanuras, etc., que se anteponen para dar origen a verdaderos "archipiélagos" humanos, convertidos posteriormente en las nuevas naciones, vecinas y distantes de Colombia y Ecuador.

A la luz de esta serie de antecedentes, queda claro que el poblamiento fragmentado, que incidió en el nacimiento de estas dos naciones andinas, daría lugar a nuevos conflictos por resolver en los años porvenir. Uno de los cuales derivó, precisamente, de la debilidad económica a la cual se vieron sometidas las jóvenes naciones que, tras alcanzar su independencia del poder colonial de España, tardaron en consolidar los mecanismos que les permitieran un eficaz manejo de su soberanía, comenzando por la delimitación y defensa de sus fronteras; al ser este último aspecto uno de los de mayor repercusión frente al tema del conflicto armado colombiano y su incidencia en el territorio ecuatoriano.

\section{VECINDAD Y CONFLICTO}

Los conflictos fronterizos aparecen como una variable en las relaciones que sostienen los países en la región desde la época precolombina y colonial, eso explica, por ejemplo, la postura asumida por Ecuador al ver perturbada su soberanía territorial frente a Perú por el control de la desembocadura del río Amazonas, asunto que con el paso del tiempo adquirió las dimensiones de un serio problema, que requirió para su solución de la mediación internacional, y dicho sea

7 Véase más sobre el concepto de "Archipiélago Biológico" en Julio Londoño, Nueva geopolítica de Colombia, Bogotá, Publicaciones de las Fuerzas Militares, 1948, p. 109. 
de paso convertiría el tema de fronteras en un aspecto de vital importancia no sólo para la reivindicación nacionalista de los ecuatorianos, sino también en un tema de primer orden en su agenda de política internacional. ${ }^{8}$

Respecto al "adelgazamiento" territorial de Colombia, a diferencia de la postura asumida por Ecuador, éste no se debió a la perturbación ocasionada por los países vecinos, sino que se trató de la adopción de medidas voluntarias emprendidas por la élite capitalina de Bogotá, cuyo escaso interés en la conservación de sus posesiones extendidas en la parte norte hasta las costas nicaragüenses y costarricenses ${ }^{9}$ al sur, en los llamados espacios "vacíos", que se han mencionado antes, comprendidos entre la selva amazónica y los llanos de la Orinoquía, se convertiría en la antesala para la formación de territorios independientes como se produciría más tarde con la separación de Panamá (1903) y, luego, con la consolidación de espacios que fueron quedando a merced de colonos, y hoy en día de agrupaciones armadas como la guerrilla o los paramilitares, quienes ejercen su dominio al aprovechar la escasa presencia del Estado en dichas zonas del país.

Desde esta perspectiva, y aunado al mencionado asunto del poblamiento fragmentado, el tema de las fronteras es un aspecto toral en el devenir de las relaciones entre Colombia y Ecuador a partir de la primera década del siglo xxI,

8 "El conflicto entre ambos países existe desde su constitución como estados. Las fronteras coloniales, débilmente definidas, han sido el centro del relato histórico nacional de Ecuador y Perú, en el caso ecuatoriano sobre todo, la fuente más sólida de identidad nacional. En 1941 hubo una guerra entre los dos países, luego de la cual se fijaron las fronteras a través de un instrumento jurídico, el Protocolo de Río de Janeiro, suscrito en 1942 en la reunión de ministros de Relaciones Exteriores del continente... (cabe señalar) en la perspectiva ecuatoriana, el Protocolo, que se firmó mientras fuerzas peruanas ocupaban territorio de Ecuador, consagra la pérdida de cerca de cincuenta por ciento de su superficie". Adrián Bonilla, "Las relaciones entre Ecuador y Estados Unidos: entre el sobresalto y la rutina", en Andrés Franco [ed.], EE.UU. y los paises andinos, 1993-1997: poder y desintegración, Bogotá, Ceja, Pontificia Universidad Javeriana, 1998, p. 99.

9 Luego de la desintegración de la Gran Colombia, la nueva República de Colombia se extendía desde la parte norte en la Costa de Mosquitos (actualmente la parte de Nicaragua sobre el Caribe), en los límites con Honduras, y seguía por el Atlántico hasta el río Esequibo (centro de la República de Guyana), de ese río hasta el Macizo Guayanés atravesándolo hasta llegar al río Negro, y saltando sobre éste hasta alcanzar el Amazonas para salir al Pacífico y torcer hacia el norte hasta llegar a Costa Rica. Londoño, op. cit., p. 33. 
debido al carácter estratégico que éstas adquieren ante la complejidad de factores internos y externos que convergen, uno de los asuntos relevantes es el desbordamiento del conflicto armado colombiano y la presencia de Estados Unidos a través de sus bases militares en el área.

\section{FRONTERA Y CONFLICTO ARMADO}

Uno de los principales problemas que se observa a lo largo de los casi 600 kilómetros de frontera que comparten Colombia y Ecuador se deriva del flujo masivo de colombianos, quienes huyendo de la violencia generalizada por causa del conflicto armado en su país, se han visto obligados en los últimos años no sólo a convertirse en desplazados al interior de Colombia, ${ }^{10}$ sino además en refugiados que traspasan las fronteras de los países vecinos en busca de amparo y protección para sus vidas. ${ }^{11}$

Lo anterior nos lleva a reflexionar sobre la relación que guarda el mencionado asunto del poblamiento fragmentado, y las repercusiones de la cada vez

${ }^{10}$ Hacia finales de 2008, el gobierno de Colombia ya había registrado más de 2.8 millones de desplazados internos en el país. Por su parte, la Consultoría para los Derechos Humanos y el Desplazamiento (CODHES) consideran que la cifra real de desplazados por el conflicto armado interno desde mediados de los años ochenta supera los 4 millones de personas. En el caso de los refugiados colombianos en Ecuador, las autoridades ecuatorianas consideran que cerca de 500000 colombianos viven en el país. En http://www.acnur.org/t3/crisis/crisis-humanitaria-encolombia/desplazamiento-interno-en-colombia/y PMA, Informe trianual 2005-2007, Quito, 2008.

${ }^{11}$ Sobre las fronteras terrestres de Colombia, cabe señalar que con Venezuela comparte aproximadamente $2219 \mathrm{~km}^{2}$, teniendo como principal límite el curso del río Orinoco. La frontera con Brasil comprende cerca de $1645 \mathrm{~km}^{2}$, los cuales se extienden desde la Piedra del Cocuy hasta la desembocadura del río San Antonio en el Amazonas. Mientras que con Perú, la frontera es de $1626 \mathrm{~km}^{2}$ y converge en la llamada zona del Trapecio Amazónico, cuyo límite natural se atribuye a los ríos Amazonas y Putumayo. Por su parte, la frontera entre Ecuador y Colombia abarca $590 \mathrm{~km}^{2}$. Por último, el límite de $266 \mathrm{~km}^{2}$ se extiende desde el océano Pacífico hacia el este, pasando por las dos Cordilleras de los Andes hasta la Amazonia. Con Panamá se encuentra interrumpido por el llamado Tapón del Darién, considerado un "verdadero vacío humano", debido a las extremas condiciones que brinda la selva húmeda y tropical en esta zona. Julio Londoño, Colombia interpretación geopolítica, Bogotá, 1971, p. 99 y Centro Andino de Estudios Internacionales (CAEI), "Diagnóstico de la frontera Ecuador-Colombia", en Consuelo Ahumada y Telma Angarita [eds.], Conflicto y fronteras en la región andina, Bogotá, Pontificia Universidad Javeriana, 2004, p. 113. 
mayor internacionalización del conflicto armado colombiano en la región andina, de la que también forma parte Ecuador.

Lo primero es que hablar del conflicto armado en Colombia nos remite al problema, antes señalado, de la falta de una visión integradora por parte de las autoridades estatales colombianas, que logre acercar o intercomunicar ese sinnúmero de porciones del territorio disímiles y aisladas que se han convertido con el paso del tiempo en auténticos "archipiélagos biológicos", tal como lo asegura Londoño, no sólo desde el punto de vista geográfico sino también político y partidista e incluso militar; lo que, al mismo tiempo, ha servido para propiciar un clima idóneo para la formación de organizaciones al margen de la ley, dentro de éstas figuran las guerrillas, que estuvieron aglutinadas en organizaciones de autodefensa campesina vinculadas al partido liberal, las cuales más tarde, con el influjo de las ideas comunistas, guevaristas y maoístas impuestas en distintas partes del mundo, adquirieron mayor fuerza y apoyo externo e interno para contender contra el aparato del Estado, por el control de aquellos espacios "vacíos", lo que daría como resultado el poblamiento de aquellos lugares de escaso interés para las autoridades citadinas de Bogotá; todo esto en medio de lo que algunos expertos, en el caso colombiano, han denominado como el proceso de "colonización armada". Tal como se fue presentando, por ejemplo, en la región de los Llanos Orientales, actualmente en el Departamento del Meta, donde se concentró desde entonces la cúpula militar de guerrillas tan renombradas hasta hoy como las Fuerzas Armadas Revolucionarias de Colombia (FARC). ${ }^{12}$

Sobre esta guerrilla, la primera en importancia en Colombia, cabe señalar que en un inicio buscó erigirse, dadas las condiciones geográficas del país, en una especie de "república independiente", al margen de la jurisdicción del aparato central de gobierno de Bogotá. Para lo cual, en 1953, sus ideólogos buscaron

12 En 1966, en el momento en que se crean las FarC, el X Congreso del Partido Comunista reitera su tesis de la "combinación de todas las formas de lucha", al colocar en primer lugar al proletariado y acuerdan asociar "la lucha de las masas" a la lucha armada para asegurar el éxito frente al ejército y la policía. Véanse más detalles en los textos del Congreso dirigido por el Frente Patriótico de Liberación Nacional. Daniel Pécaut, Orden y violencia: Colombia, 1930-1953, Bogotá, Siglo XXI/CEREC, 1987, p. 60. 
la creación de un "Estado mayor y comando supremo del movimiento guerrillero-revolucionario de los Llanos Orientales", al mando del comandante general Guadalupe Salcedo, que estaría guiado por las leyes consagradas en una especie de constitución propia, conocida como "Las Leyes del Llano" (1952), ${ }^{13}$ en cuyo contenido estarían reflejados varios de los principios autonomistas y comunistas que servirían de base para constituir esta pretendida "república independiente".

El problema para el gobierno era que mientras se buscaba reducir el margen de maniobra de esta agrupación campesina en los Llanos Orientales, surgían nuevas organizaciones rurales en distintos puntos del país, empeñadas en erigirse como "repúblicas independientes". ${ }^{14}$ Efectivamente, el limitado interés de la dirigencia central del Estado colombiano por ejercer su soberanía en lugares tan disímiles y apartados, terminó favoreciendo, de cierta manera, que fueran las propias autodefensas campesinas las que se encargarían de ejercer un poder de facto, a partir del cual se asumirían como una especie de "pseudo-estados"; cuya funcionalidad dependería de sus capacidades para organizar el territorio, la población, impartir justicia y administrar recursos financieros.

Al analizar la formación de estas primeras organizaciones armadas y sus repercusiones políticas hasta los tiempos actuales, se puede comprobar un aspecto crucial en el ámbito del desarrollo del Estado colombiano y su relación con los países vecinos, que se vincula precisamente con el persistente aislamiento y la marginación de las unidades geográficas del territorio colombiano, situación

${ }^{13}$ Dividida en siete títulos así: 1) De la población civil, 2) Del gobierno popular, 3) De las autoridades superiores, civiles y militares, 4) Delitos y penas, 5) Administración de justicia, 6) De la fuerza armada y la tropa, 7) Disposiciones varias. Alfredo Vásquez Carrizosa, Relatos de la historia diplomática de Colombia, siglo XX, Bogotá, Cancillería de San Carlos, Pontificia Universidad Javeriana, t. I, 2000, p. 153.

14 Producto del continuo proceso de "colonización armada" de las tierras fértiles, latifundios y aquellos espacios vacíos en Colombia, dieron lugar a una respuesta inmediata de la dirigencia que venía acompañada del sentir de los hacendados y de los empresarios, que se veían perturbados por la resistencia campesina y la de sus trabajadores; lo cual trajo como consecuencia una serie de acuerdos entre el gobierno de Colombia y de Estados Unidos, todo ello al calor de la llamada Doctrina de Seguridad Hemisférica, creada para frenar la expansión del comunismo en toda América. Para más información sobre las Farc, se recomienda el texto de Francisco Leal Buitrago, Estado y política en Colombia, Bogotá, Siglo xxI, 1984, p. 213. 
que se ve reflejada en el marcado regionalismo y en esa condición perenne que brindan los "archipiélagos biológicos", de los cuales surge entonces la reivindicación de supuestas repúblicas independientes al interior de este territorio.

Desde esta perspectiva, el problema estriba en que al seguir frenando a este tipo de unidades geográficas, igualmente se continúa manteniendo el tradicional modelo geopolítico de la fragmentación territorial, heredado de la época precolombina y virreinal, que en las últimas décadas se ha transformado en un tipo de conflicto armado o de guerra civil, como consecuencia de una disputa por el control político y por la distribución de tierras, en este último aspecto hay una salvedad, ya que precisamente la importancia que ahora le da el gobierno central a esos territorios, antes marginales, estriba en la relevancia estratégica que representan comercialmente varios de estos espacios de la geografía gracias a sus enormes reservas petroleras, acuíferas e hídricas, ${ }^{15}$ además de que por sus propias características se puede hablar de suelos fértiles y selvas vírgenes, cuya utilidad ha sido aprovechada por las propias agrupaciones armadas, las cuales se encargan de la producción y comercialización ilegal de hoja de coca y amapola empleada en la elaboración de narcóticos. ${ }^{16}$

Dentro de esa dinámica por el control político, territorial y estratégico en estos últimos tiempos, un dato que muestra el progresivo avance que se ha dado en esta materia se observa en la capacidad de control adquirida por guerrillas rurales como las FaRC, que para el 2000 se hizo presente en por lo menos $622 \mathrm{mu}-$ nicipios de un total de 1050 distribuidos en todo el país. ${ }^{17}$

15 "Los Andes amazónicos representan 60\% de las reservas de hidrocarburos - carbón, petróleo y gas-de América Latina". Javier Sanín, "El calentamiento de las fronteras andinas", en Ahumada y Angarita, op. cit., p. 15.

${ }^{16}$ De acuerdo con el general brasileño Augusto Heleno Ribeiro, comandante de la Amazonia brasileña, "que guerrilleros de las Fuerzas Armadas Revolucionarias de Colombia (FARC) entran como ciudadanos comunes a Brasil para abastecerse en el comercio y muchas veces utilizan como moneda de cambio la pasta de cocaína", debido también al tráfico fluvial que ahora se viene intensificando más que el aéreo en toda esta zona expuesta al comercio y la distribución de narcóticos para el resto del Brasil. "Comandante de la Amazonia brasileña advierte presencia de las FARC en Brasil", Agencia EFE, Sao Paulo, 20 de abril, 2008.

17 "En 1999, las FarC-EP habían aumentado su poder más allá de 60\% del país, y en menos de tres años se estimaba que más de 93\% de todas las "regiones de población reciente", en Colombia 
Otro aspecto que se deriva de la progresiva presencia de las guerrillas a través de sus cerca de 150 frentes, distribuidos en siete bloques - Oriental, Occidental, Sur, Central, Magdalena Central, Caribe, César- ${ }^{18}$ es la formación de nuevas entidades territoriales con un tipo de mando o autoridad que no es precisamente del gobierno, sino que se encuentra representada por miembros de las guerrillas, lo que a su vez nos permite hablar de una prolongación del conflicto armado hacia las zonas de frontera con los cinco países vecinos: Ecuador, Perú, Brasil, Venezuela y Panamá. ${ }^{19}$

Ante este progresivo aumento de la guerrilla a todo lo largo y ancho del cordón fronterizo que rodea al país, las autoridades del gobierno en Colombia decidieron implementar una nueva estrategia, similar a la adoptada en décadas anteriores con el llamado "Plan Lazo"20 para el combate a las denominadas "repúblicas independientes", que cuenta además con el apoyo financiero y el asesoramiento militar de los estadounidenses en el marco de las tareas de contrainsurgencia a las que se refiere el actual "Plan Colombia" (1998), y que durante la administración del presidente colombiano, Álvaro Uribe Vélez (20022010), adoptó el nombre de "Plan Patriota". Dicho plan se mantiene en consonancia con los objetivos trazados por los intereses estadounidenses para su-

tenían una presencia de la guerrilla. Un ejemplo es el Departamento de Cundinamarca, que cerca completamente a la ciudad capital de Bogotá. En esta área el poder de las FARC-EP se extiende a través de 83 de las 116 municipalidades". James J. Brittain, "Las FARC-EP en Colombia, una excepción revolucionaria en una era de expansión imperialista", en Montbly Review, vol. 57, núm. 4, Nueva York, septiembre, 2005. En http://www.rebelion.org/noticia.php?id=23095.

18 "En cada uno de estos bloques hay un número de frentes que contienen, en promedio de 300 a 600 combatientes por unidad", en ibid., p. 5.

19 Daniel Pécaut, "Conflicto sin frontera", en Ahumada y Angarita, op. cit., pp. 80 y 81.

${ }^{20}$ El llamado "Plan Lazo" en Colombia, consistió en una serie de bombardeo en aquellos territorios ocupados por liberales y comunistas en áreas como las de Marquetalia (en el Departamento del Tolima), Ríochiquito (zona indígena en el norte del Dep. de Cauca), el Pato y Guayabero (ubicados en la parte de la Cordillera Oriental que divide al Dep. del Huila, Caquetá y del Meta) y Sumapaz (Dep. Cundinamarca), cuyo efecto más inmediato se dio a partir del éxodo de los sobrevivientes de los departamentos antes citados, que se mudaron en dirección a la región de los Llanos Orientales, situación que dio inicio formal a las actividades guerrilleras de las FARC a partir de 1964 hasta la fecha. Buitrago, op. cit., p. 214. 
pervisar desde territorio colombiano las acciones emprendidas por la insurgencia, y obviamente por parte de los cinco países vecinos de Colombia que convergen en la denominada región andino-amazónica, en la que se incluye a Brasil. ${ }^{21}$

\section{ESTADOS UNIDOS Y EL "BLINDAJE" DE LAS FRONTERAS ANDINAS}

Desde esa perspectiva, la respuesta militarista del actual gobierno de Colombia frente al despliegue de los grupos armados irregulares ${ }^{22}$ viene acompañada de un llamado para que sus vecinos se sumen a "la cruzada en contra del terrorismo", que se adoptó con mayor ahínco tras la caída de las Torres Gemelas en Estados Unidos, en el marco de la Estrategia de Seguridad del entonces presidente George Bush (2001), y que fuera seguida por el presidente Uribe, tal como lo advierten sus declaraciones en Quito, al comparar la situación del conflicto armado en Colombia con la situación de Iraq. En ellas dice que de no poner freno a la expansión de las guerrillas colombianas se estaría cada vez más ante una progresiva "pérdida de soberanía nacional" en manos de los actores armados irregulares, y ante una mayor exacerbación del conflicto en toda la región. ${ }^{23}$

Así, la puesta en marcha de los planes de militarización de Colombia, lo han convertido, antes de 2009, en lo que bien podría denominarse como "el portaviones de Estados Unidos en Sudamérica". Es decir, en el centro de sus operaciones, al apoyar los requerimientos y exigencias del Comando del Sur norteamericano, desde donde se coordinan numerosas tareas de inteligencia,

${ }^{21}$ Según "la Estrategia de Seguridad Nacional - diciembre de 2001- localiza dentro de las fronteras colombianas el epicentro terrorista de mayor riesgo para el continente, y, en consecuencia, al que más le invierte: la región andina es hoy el tercer receptor de ayuda militar norteamericana, después del Oriente Medio e Israel". Sanín, op. cit., p. 13.

${ }^{22}$ De acuerdo con el trabajo de campo adelantado por el periodista James Brittain, "las FARC-EP tienen cerca de 105 frentes, una media de 300 a 600 insurgentes por frente. (Lo que da como resultado) una media conservadora de 46000 combatientes de las FARC-EP, entre 2002 y 2004 ", precisamente en la época en que se implementó el Plan Patriota. Véase más sobre el tema en James J. Brittain, "Las FARC-EP en Colombia, una excepción revolucionaria en una era de expansión imperialista", en op. cit., p. 6.

${ }^{23}$ Ricardo Soberón Garrido, "Fronteras y conflicto: realidades, intereses y perjuicios", en Ahumada y Angarita, op. cit., p. 29. 
contrainsurgencia, interdicción y otras que adelanta Estados Unidos a través de sus puestos de avanzada, conocidos como Foward Operacional Locations (FOL) ${ }^{24}$ distribuidos en diferentes puntos del Caribe, Centroamérica y Sudamérica.

Tras la implementación del Plan Colombia, en 1998, vienen operando tres modernos batallones en la parte sur del país (Larandida, Puerto Leguizamo y Tres Esquinas) y se espera que entren en funcionamiento, durante la administración del presidente Barack Obama, cinco bases más, distribuidas en los cuatro puntos cardinales del territorio colombiano, que son: la de Palanquero, la Alberto Pouwels, la de Apiay, la de Tolemaida y la de Málaga.

Entre tanto, el gobierno ecuatoriano, desde la adopción del Plan Colombia, buscó "reforzar la capacidad operativa de sus Fuerzas Armadas, alcanzar un elevado grado de aislamiento y capacidad de acción inmediata, y mejorar la inteligencia para operaciones militares en la zona". ${ }^{25}$ Dichos objetivos lo llevaron a incrementar la presencia militar en las provincias fronterizas, en especial en Sucumbíos y Esmeraldas; lo que además justifica la apertura en 1999 de la Base de Manta, mediante la cual se recibió asistencia militar antinarcóticos por parte de Estados Unidos cercana a los 24428 millones de dólares en $2001 .^{26}$

Sin embargo, tras el ascenso al poder del presidente Rafael Correa (2007), Ecuador asumió un nuevo viraje en sus relaciones con el hegemón, y declaró que no autorizaría más la presencia militar de Estados Unidos en la Base de Manta, lo cual explica el traslado de la infraestructura de Manta al vecino territorio colombiano a través de las cinco bases antes mencionadas, para de este modo avanzar en los planes de "blindaje" y supervisión de la región andina, no sólo en lo referente a la lucha contrainsurgente y antinarcóticos, sino también en lo relacionado con el control y aprovisionamiento de recursos estratégicos como el petróleo y otros que abundan en la zona.

24 Ibid., p. 28.

${ }^{25}$ Centro Andino de Estudios Internacionales (CAEI), "Diagnóstico de la frontera..., pp. 128 y 129

${ }^{26}$ Ibid., p. 128. 
Sobre el asunto del petróleo, éste se ha convertido en un excelente puntal de la economía del Ecuador, gracias a sus probadas reservas de crudo que ascienden a más de 2.1 mil millones de barriles, con una producción bruta que en 2001 fue de 415000 barriles diarios, los cuales se extraen principalmente de sus yacimientos situados al este de la Amazonia, en la provincia de Oriente. Estos datos explican de cierta manera que la presencia militar estadounidense siga presente, y vigilante del Ecuador desde el lado de Colombia, no sólo por el carácter estratégico de su petróleo, sino además por los efectos que trae consigo la inminente alianza entre el presidente Correa de Ecuador y el presidente de Venezuela, Hugo Chávez Frías, este último considerado uno de los principales líderes de la izquierda y promotor del antiimperialismo en toda América Latina.

Respecto al tema de las relaciones entre Colombia y Ecuador, el asunto que propició la ruptura diplomática entre ambos países se debió a la incursión del ejército de Colombia a la región fronteriza de Angostura en Ecuador, donde murieron varios uniformados de la guerrilla de las FARC, quienes operaban de ese lado del territorio de Ecuador, encontrándose allí uno de los principales miembros de esta organización irregular.

Dichos ataques al territorio fronterizo con Ecuador se convertirían en la manzana de la discordia y en el tema central de numerosos encuentros de presidentes de toda América Latina, los que tanto en la Organización de Estados Americanos (OEA), la Cumbre de Países del Grupo de Río, la Unión de Naciones Suramericanas (UNASUR) y otros foros de renombre internacional han planteado su preocupación frente a estos actos, considerados para algunos como una violación perenne a la soberanía, tal como lo argumenta Ecuador, mientras que para Colombia y quienes la apoyan como Estados Unidos, se trató de un acto de legítima defensa en contra de las acciones emprendidas por el terrorismo. ${ }^{27}$

${ }^{27}$ Véase más del tema en Luis Dallanegra, "El derecho internacional y los límites a la violencia", en Revista Reflexión Política, vol. 11, núm. 21, Bucaramanga, Instituto de Estudios Políticos de la Universidad Autónoma de Bucaramanga (UNAB), junio, 2009. En http://uisdallanegra. bravehost.com/Amlat/derintlv.htm 
Por todo ello, desde marzo de 2008, las relaciones diplomáticas entre Colombia y Ecuador se han quedado en el limbo, el panorama inmediato entre estas dos hermanas repúblicas no avizora la reanudación amistosa de sus relaciones, por el contrario, la puesta en marcha de las nuevas bases militares estadounidenses en territorio colombiano altera y modifica la convivencia entre los miembros de la región andino-amazónica, varios de los cuales han tomado la decisión de equipar sus ejércitos con armas de última generación, que se venden y ofrecen en los mercados internacionales; todo esto como una estrategia preventiva y a la vez ofensiva ante la posibilidad de una agresión armada en territorios, aparentemente, blindados por la selva, pero susceptibles de convertirse en futuros escenarios de guerra. ${ }^{28}$

\section{REFLEXIONES FINALES}

De este análisis sobre las relaciones entre Colombia y Ecuador, podemos comprobar la persistencia de un serio problema que atañe a nuestros países, el cual tiene que ver directamente con la escasa atención que se le sigue prestando a las zonas de frontera. Ciertamente se trata de porciones del territorio fragmentado en las que converge un complejo espacio, distante de los centros de decisión política, lo que a su vez genera un ambiente difícil para la sobrevivencia de muchos de sus pobladores, esto debido a las constantes disputas que se presentan entre los diferentes actores armados (guerrilla, paramilitares, ejército, traficantes, etc.) que intentan hacer prevalecer su poder por encima de otros, en la mayoría de los casos a través de la violencia.

Estos territorios merecen una debida atención gubernamental, sobre todo cuando se observa en cada territorio limítrofe la existencia de una amplia variedad de pueblos que coexisten tal como sucede con los refugiados colombianos, quienes traspasan las fronteras de un país a otro, a pesar de las adversidades que este

${ }^{28}$ Al respecto, el presidente Hugo Chávez afirma que "la instalación de bases militares en Colombia es una estrategia global de guerra ideada por Estados Unidos". Véase más en http://www. telesurtv.net/noticias/secciones/nota/61470-NN/chavez-aclara-que-no-ha-llamado-a-la-guerrasino-a-defender-la-soberania/ (fecha de consulta: 20 de noviembre, 2009). 
acto conlleva, y que, por consiguiente, se convierte en un fenómeno que genera nuevas formas de convivencia, algunas veces de forma hostil, pero en otros casos dando lugar a la creación de nuevas identidades que se entremezclan o se diferencian entre sí.

Aunado a lo anterior, el componente militar del cual se hizo mención en este ensayo, nos permite dilucidar un escenario sombrío para la región, debido a las políticas adoptadas por el hegemón, en este caso por Estados Unidos, que en el afán de garantizar su propia seguridad y de reactivar una "economía de guerra", en medio de la crisis financiera global de estos últimos años, se mantiene firme ante su tradicional estrategia de alentar las diferencias y los conflictos existentes entre nuestros países. Prueba de ello es la colocación de numerosas bases militares en territorio colombiano, según esto para contrarrestar los efectos nocivos del narcotráfico y de la guerrilla que afecta no sólo a Colombia, sino también al resto de países en la región, lo que dicho sea de paso ha convertido a esta nación, gracias también a su ubicación geográfica entre el Caribe y Sudamérica, en una especie de "portaviones de los estadounidenses" en pleno corazón de América.

Recibido: 4 de noviembre, 2009.

Aceptado: 3 de marzo, 2010.

\section{BibLiografía}

BonILLA, ADRIÁn, "Las relaciones entre Ecuador y Estados Unidos: entre el sobresalto y la rutina", en Andrés Franco [ed.], EE.UU. y los países andinos, 19931997: poder y desintegración, Bogotá, Ceja, Pontificia Universidad Javeriana, 1998.

BRITTAIN, JAMES, "Las FARC-EP en Colombia, una excepción revolucionaria en una era de expansión imperialista", en Monthly Review, vol. 57, núm. 4, Nueva York, septiembre, 2005. En http://www.revelion.org/noticia.php2id=23095.

BROADBENT, SYLVIA, Los chibchas: organización social y politica, Bogotá, Facultad de Sociología, Universidad Nacional de Colombia, 1964. 
Buriano CaSTro, Ana, Ecuador, México, Instituto Mora, 2000.

Bushnell, David, Colombia una nación a pesar de si misma. De los tiempos precolombinos a nuestros días, Bogotá, Planeta, 1996.

Cárdenas Arroyo, Felipe, "América: tres civilizaciones y numerosas sociedades intermedias", en Revista Credencial Historia, núm. 34, Bogotá, octubre, 1992.

Centro Andino de Estudios Internacionales (Caei), "Diagnóstico de la frontera Ecuador-Colombia", en Consuelo Ahumada y Telma Angarita [eds.], Conflicto y fronteras en la región andina, Bogotá, Pontificia Universidad Javeriana, 2004.

Dallanegra, Luis, "El derecho internacional y los límites a la violencia", en Revista Reflexión Política, vol. 11, núm. 21, Bucaramanga, Instituto de Estudios Políticos de la Universidad Autónoma de Bucaramanga (UNAB), junio, 2009. En http://uisdallanegra.bravehost.com/Amlat/derintlv.htm.

Leal Buttrago, Francisco, Estado y política en Colombia, Bogotá, Siglo XXI, 1984. LIÉvano AguirRe, Indalecio, Bolivarismo y monroísmo, Bogotá, Tercer Mundo Editores, 1987.

Londoño, Julio, Nueva geopolítica de Colombia, Bogotá, Publicaciones de las Fuerzas Militares, 1948.

, Colombia interpretación geopolítica, Bogotá, 1971.

MontaÑa Cuellar, Diego, Colombia: país formal y país real, Buenos Aires, Platina, 1963.

Nogué Font, Joan y Joan Vicente Rufí, Geopolítica, identidad y globalización, Barcelona, Ariel Geografía, 2001.

Palacios, Marco, País fragmentado, sociedad dividida, su historia, Bogotá, Norma, 2002.

Pécaut, Daniel, Orden y violencia: Colombia, 1930-1953, Bogotá, Siglo xxI/CEREC, 1987.

PICón, Delia, Historia de la diplomacia venezolana, Caracas, Universidad Católica Andrés Bello, 1999.

SANín, JAVIER, "El calentamiento de las fronteras andinas", en Consuelo Ahumada y Telma Angarita [eds.], Conflicto y fronteras en la región andina, Bogotá, Pontificia Universidad Javeriana, 2004. 
SANTANA, AdalberTo, "Golpe de Estado en Honduras", en Archipiélago. Revista cultural de nuestra América, año 17, núm. 65, México, Cialc-unam, julioseptiembre, 2009.

, "Crisis en Honduras", en Cuadernos Americanos. Nueva Época, vol. 4, núm. 130, México, CIALC-unam, octubre-diciembre, 2009. Soberón GARRIDO, Ricardo, "Fronteras y conflicto: realidades, intereses y perjuicios", en Consuelo Ahumada y Telma Angarita [eds.], Conflicto y fronteras en la región andina, Bogotá, Pontificia Universidad Javeriana, 2004.

Vázquez Carrizosa, Alfredo, Relatos de la historia diplomática de Colombia, siglo XX, Bogotá, Cancillería de San Carlos, Pontificia Universidad Javeriana, t. I, 2000.

\section{PÁGINAS ELECTRÓNICAS}

http://www.bbc.co.uk/mundo/economia/2009/08/090811_1528_crisis_econo mia_jg.shtml.

http://www.acnur.org/t3/crisis/crisis-humanitaria-encolombia/desplazamiento-interno-en-colombia/y PMA, Informe trianual 2005-2007, Quito, PMA, 2008.

http://www.rebelion.org/noticia.php?id=23095.

http://uisdallanegra.bravehost.com/Amlat/derintlv.htm.

http://www.telesurtv.net/noticias/secciones/nota/61470-NN/chavez-aclaraque-no-ha-llamado-a-la-guerra-sino-a-defender-la-soberania/.

\section{HeMEROGRAFíA}

"Comandante de la Amazonia brasileña advierte presencia de las farc en Brasil", en Agencia EFE, Sao Paulo, 20 de abril, 2008. 